\title{
A comparison of spectrophotometric and denuder based approaches for the determination of gaseous molecular iodine
}

\author{
R. J. Chance ${ }^{1}$, M. Shaw ${ }^{1}$, L. Telgmann ${ }^{1,2}$, M. Baxter ${ }^{3}$, and L. J. Carpenter ${ }^{1}$ \\ ${ }^{1}$ Department of Chemistry, University of York, York, YO10 5DD, UK \\ ${ }^{2}$ Department of Chemistry, University of Münster, Münster, 48149, Germany \\ ${ }^{3}$ The Food and Environment Research Agency, Sand Hutton, York, YO41 1LZ, UK
}

Received: 18 August 2009 - Published in Atmos. Meas. Tech. Discuss.: 24 September 2009

Revised: 15 January 2010 - Accepted: 25 January 2010 - Published: 9 February 2010

\begin{abstract}
The presence of molecular iodine in the atmosphere is thought to have implications for both climate and human nutritional health, but measurement of the gas at low concentrations requires technically demanding techniques that are not widely accessible. Here, amylose coated denuder tubes and solvent traps coupled with spectrophotometric detection are evaluated and compared as relatively cheap and straightforward methods to measure gaseous molecular iodine at environmentally relevant concentrations. Denuder tubes were found to give unacceptably low and highly variable recoveries of molecular iodine from a test gas source, with values ranging from 1 to $62 \%$. Blank concentrations were also high, being equivalent to a gas phase concentration of 5 pptv under typical operating conditions. Ethanol and hexane solvent traps gave much better performance. Optimisation of the hexane solvent trap method gave $100 \%$ recovery and an atmospheric limit of detection of $70 \mathrm{pptv}$, which is within the range of concentrations observed in the coastal marine atmosphere.
\end{abstract}

\section{Introduction}

Understanding the biogeochemical cycle of iodine is important for three reasons: volatile iodine compounds are photolysed in the atmosphere to give iodine atoms which are implicated in ozone destruction and particle formation reactions and may thus impact climate (O'Dowd and Hoffmann, 2005); iodine is an essential human nutrient, deficiency of which remains the leading cause of preventable brain damage and mental retardation worldwide (WHO, 2004); the longlived radionuclide iodine-129 is released to the environment

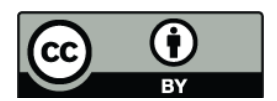

Correspondence to: R. Chance (rjc508@york.ac.uk) by the nuclear industry (Raisbeck and Yiou, 1999). Marine formation (biotic and abiotic) followed by sea-air exchange is the main route by which iodine enters the atmosphere. Atmospherically processed iodine is subsequently deposited on land and incorporated into terrestrial food chains.

Molecular iodine has been observed in the coastal marine atmosphere at concentrations ranging from $<0.2$ to $93 \mathrm{pptv}$ (Saiz-Lopez et al., 2006b; Finley and Saltzman, 2008). It is thought to be either released directly by exposed macroalgae at low tide or formed by the reaction of ozone and iodide on the surface of the algal fronds (Palmer et al., 2005; Kupper et al., 2008; Dixneuf et al., 2009). It may also be formed by the reaction of ozone and iodide at the ocean surface (Garland and Curtis, 1981), but as yet no open ocean measurements of atmospheric molecular iodine have been reported. Underice microalgal production of molecular iodine has also been suggested as a source of atmospheric reactive iodine in polar oceanic regions (Saiz-Lopez and Boxe, 2008). For all of these environments, the processes and fluxes by which molecular iodine may be formed and volatilised are not yet fully understood.

One of the hindrances in this field is the lack of a readily accessible, straightforward yet robust means of measuring molecular iodine in the gas phase at low concentrations approaching those encountered in the atmosphere. Typically, atmospheric measurements of molecular iodine are made using long path differential optical absorption spectroscopy (LP-DOAS; Saiz-Lopez et al., 2006b). However, this yields concentrations averaged over a path length of several kilometres so is unsuitable for point measurements and cannot be used on board a ship for open ocean measurements. Advances have been made in the use of broadband cavity enhanced absorption spectroscopy (BBCEAS) for the measurement of gaseous molecular iodine in situ (Saiz-Lopez et al., 2006a; Dixneuf et al., 2009), but this approach is also technically demanding and is unavailable to the majority of

Published by Copernicus Publications on behalf of the European Geosciences Union. 
researchers. Recently, atmospheric pressure chemical ionisation tandem mass spectrometry (APCI-MS-MS) has also been applied to the measurement of molecular iodine in air (Finley and Saltzman, 2008).

The use of diffusion denuders with either a starch (Chen et al., 2006; Saiz-Lopez et al., 2006a) or an alpha-cyclodextrin coating (Huang and Hoffmann, 2009) to measure molecular iodine in the coastal atmosphere has been reported. At higher concentrations, gas phase molecular iodine can be measured using a solvent trap followed by spectrophotometric detection (Palmer et al., 2005). These methods have the advantage of being straightforward, specific, relatively cheap and able to produce time-averaged rather than spatially-averaged measurements. Additionally, if using denuders the possibility exists for samples to be collected and analysed at a later date. Here we evaluate and compare the applicability of starch coated denuders and ethanol and hexane solvent traps for the measurement of molecular iodine at atmospherically relevant concentrations.

\section{Experimental}

\subsection{Generation of a molecular iodine test source}

A permeation oven (Kin-Tek ${ }^{\mathrm{TM}}$, USA) fitted with a commercial molecular iodine permeation tube (Kin-Tek ${ }^{\mathrm{TM}}$, USA) was used to provide a constant source of gaseous iodine for evaluation of the detection methods. The oven temperature was either 30 or $60^{\circ} \mathrm{C}$ according to the required concentration. Iodine emission rates at these operating temperatures were determined directly by repeated weighing of the tube at approximately two week intervals. The permeation chamber was flushed with zero grade nitrogen (BOC) at a flow rate of $0.05 \mathrm{~L} \mathrm{~min}^{-1}$. The outlet flow was further diluted with nitrogen, the flow rate of which was varied to achieve the desired final concentration of molecular iodine. Where required, a needle valve and T-piece was used to ensure that the outlet flow rate to the solvent trap or denuder remained constant. The range of concentrations obtainable was $190 \mathrm{pptv}$ to $285 \mathrm{ppbv}$. To minimise losses of iodine to the walls, all tubing and fittings were made of Teflon or glass and the outlet line from the oven was wrapped with heated tape $\left(\sim 60^{\circ} \mathrm{C}\right)$. The tubing was also wrapped in black tape to prevent any photodegradation of iodine. Using a hexane solvent trap (see Sect 3.2), this set up was found to give good recovery of the permeated iodine.

\subsection{Denuder tubes}

Diffusion denuder tubes are widely used for the determination of contaminants in air (Kloskowski et al., 2002). Under conditions of laminar flow, gaseous molecules are able to diffuse to the inner surface of the tubes while particles pass straight through, allowing the separation of gaseous and aerosol components. By covering the inner walls of the tube with a substrate that binds with the analyte of interest, the analyte may be trapped for subsequent determination. Molecular iodine forms a stable complex with the amylose helices in starch (Calabrese and Khan, 1999; Bates et al., 1943), so in principle a starch coating may be used to trap iodine from the gas phase (Chen et al., 2006). Chen et al. (2006) used amber glass denuder tubes $(6 \mathrm{~mm}$ internal diameter, $9 \mathrm{~mm}$ external diameter, $500 \mathrm{~mm}$ length) coated using $2 \mathrm{~mL}$ of starch in ethanol $\left(2 \mathrm{~g} \mathrm{~L}^{-1}\right)$ to detect molecular iodine in air.

\subsubsection{Preparation}

Starch coated glass denuder tubes were prepared according to the protocol given in Chen et al. (2006). The tube dimensions were $6 \mathrm{~mm}$ internal diameter, $10 \mathrm{~mm}$ external diameter and $500 \mathrm{~mm}$ length. Before coating, they were cleaned by soaking for $24 \mathrm{~h}$ in $10 \%(\mathrm{v} / \mathrm{v})$ nitric acid, rinsing thoroughly with deionised water and oven drying. A $2 \mathrm{gL}^{-1}$ suspension of ground amylose (Sigma) in ethanol (Fisher analytical grade) was prepared. Four $0.5 \mathrm{~mL}$ aliquots of the suspension were applied to the inside of the tube and the tube rotated and gently inverted to ensure even coating of the inner walls. Between each aliquot the tube was dried using a compressed air flow of $0.5 \mathrm{~L} \mathrm{~min}^{-1}$. To avoid inhomogeneous coating, the suspension was stirred regularly throughout the coating process. The tubes were then capped and sealed with laboratory film at each end and wrapped with foil and black tape to prevent light penetration.

\subsubsection{Validation experiments}

To determine the recovery and trapping efficiency of the denuders, two tubes were connected in series to the permeation oven outlet. The tubes were held in a vertical position with upward flow at a rate of $0.5 \mathrm{~L} \mathrm{~min}^{-1}$. The iodine concentration was $25 \mathrm{ppbv}$ and each pair of tubes was exposed for seven minutes. The experiment was repeated five times with freshly coated tubes and a further five times with tubes coated approximately six months earlier. Recovery and trapping efficiency (T. E.) were calculated according to Eqs. (1) and (2), respectively.

Recovery $(\%)=100 \times[\text { iodine }]_{\text {measured }} /[\text { iodine }]_{\text {expected }}$

T. E. $(\%)=100 \times[\text { iodine }]_{\text {trap } 1} /\left\{[\text { iodine }]_{\text {trap } 1}+[\text { iodine }]_{\text {trap } 2}\right\}$

Three freshly coated and three older tubes which had not been attached to the iodine source were analysed as blanks. A preliminary blank experiment in which six starch coated tubes were flushed with compressed air at a flow rate of $0.5 \mathrm{~L} \mathrm{~min}^{-1}$ was also conducted. A number of other preliminary experiments using the same conditions as described here, but differing test gas concentrations and starch types were also conducted. 
In order to determine whether the concentration of iodine in the gas stream affects recovery, the dilution flow rate on the permeation oven was varied to give four different concentrations (ranging from 14 to $21 \mathrm{ppbv}$; see Table 1 ). The outlet flow was split and a needle valve used to maintain a constant flow rate of $0.5 \mathrm{~L} \mathrm{~min}^{-1}$ through the denuders. The duration of exposure was adjusted so that the total amount of iodine passing through the tubes was the same for each concentration. As before two tubes were used in series. Replicate experiments were conducted at each gas concentration.

The stability of iodine while on the denuder tubes was evaluated by exposing six pairs of tubes to the iodine test gas as described above, and analysing three pairs immediately and three pairs after storage for one week at room temperature.

\subsubsection{Elution and analysis}

Following the method of Chen et al. (2006), denuder tubes were eluted with $4 \mathrm{~mL}$ of $5 \%(\mathrm{v} / \mathrm{v})$ tetramethyl ammonium hydroxide (TMAH; Riedel-de Haën). Each tube containing the TMAH was capped and gently inverted and rotated for $20 \mathrm{~min}$ before transfer of the eluent to a plastic sample tube. The tube was rinsed with a further $4 \mathrm{~mL}$ of ultra-pure water (MilliQ) to give a final TMAH concentration of $2.5 \%$ in the sample. Serial elutions gave iodine contents indistinguishable from solvent blanks in the second elution, suggesting this protocol was sufficient to remove the iodine from the inside of the tube. Chen et al. (2006) heated the eluate at $90{ }^{\circ} \mathrm{C}$ for three hours, but we found this to make no difference to the iodine content of extracts, blanks or iodine standards.

The iodine content of the denuder tube eluate was determined using an Elan 6000 inductively coupled plasma-mass spectrometer (ICP-MS) at the Food and Environmental Research Agency (formerly Central Science Laboratory), UK. Samples were analysed by flow injection with aspiration into the plasma via a PFA concentric nebuliser/water cooled cyclonic spray chamber combination. Sampler and skimmer cones were both platinum tipped. Instrument conditions were as follows: nebuliser gas flow $\sim 1.35 \mathrm{~L} \mathrm{~min}^{-1}$; dwell time $100 \mathrm{~ms}$; 4 sweeps per reading; 55 readings per replicate. Calibration was performed using eight external standards $(0$ to $200 \mu \mathrm{g} \mathrm{L}^{-1}$ iodine) prepared from potassium iodate in $2.5 \%$ TMAH. A bulk diluent (0.5\% TMAH) containing tellurium and antimony as internal standards (to correct for any instrument drift over the course of a run) was used to make 1:1 dilutions of all stock standards and samples prior to analysis. This ICP-MS method for iodine has been thoroughly validated using certified reference materials extracted into TMAH and is UKAS accredited to ISO 17025.
Table 1. Recoveries of iodine by denuder tubes at different iodine concentrations. Values are for the sum of two tubes in series, blank corrected and averaged for two repeat experiments (range given in parentheses).

\begin{tabular}{ccc}
\hline $\begin{array}{c}\text { Iodine concentration, } \\
\text { ppbv }\end{array}$ & $\begin{array}{c}\text { Exposure time, } \\
\text { min }\end{array}$ & $\begin{array}{c}\text { Recovery, } \\
\%\end{array}$ \\
\hline 21 & 8.4 & $1.6(1.4$ to 1.7$)$ \\
18 & 9.8 & $6.1(0.8$ to 11.4$)$ \\
15 & 11.2 & $0.7(0.6$ to 0.8$)$ \\
14 & 12.6 & $24(21.0$ to 27.5$)$ \\
\hline
\end{tabular}

\subsection{Solvent traps}

\subsubsection{Comparison of hexane and ethanol}

Molecular iodine is very soluble in both hexane and ethanol, so these solvents are both effective in stripping it from the gas phase. In $n$-hexane, molecular iodine is stable and absorbs strongly at $\sim 520 \mathrm{~nm}$ (Fig. 1a) to give a purple coloured solution. In ethanol, molecular iodine disproportionates to give a number of species including iodide $\left(\mathrm{I}^{-}\right)$, which can be quantified by its absorbance at $\sim 225 \mathrm{~nm}$ (Fig. 1b). Both hexane and ethanol solvent traps have been used to measure the evolution of iodine gas in experiments (Palmer et al., 2005; Rajendran, 2008).

Absorption spectra from 190 to $650 \mathrm{~nm}$ were measured using a PerkinElmer Lambda 25 UV/VIS spectrophotometer fitted with a $1 \mathrm{~cm}$ cell. The instrument was autozeroed using the appropriate solvent. Calibration curves were constructed using standard solutions prepared from ground molecular iodine (puriss p.a., Riedel-de Haën) dissolved in either $n$ hexane (HPLC Grade, Fisher UK) or absolute ethanol (Analytical Grade, Fisher, UK); the concentration range used was typically 500 to $5000 \mathrm{nM}$. To avoid any memory effects, the spectrophtotometer cuvettes were rinsed thoroughly with solvent between each scan and solvent blanks were run between each sample or standard. The spectrophotometric limit of detection $\left(\mathrm{LoD}_{\mathrm{spec}}\right)$ was calculated using Eq. (3) (Harris, 2002), where $\sigma_{\mathrm{STD}}$ is the standard deviation of the absorbance for repeat measurements of a mid-range standard $(n=3)$ and the sensitivity is defined as the slope of the calibration curve.

$\mathrm{LoD}_{\mathrm{spec}}=3 \cdot \sigma_{\mathrm{STD}} /$ sensitivity

Initial trials used a prototype solvent trap consisting of a $100 \mathrm{~mL}$ round bottomed flask containing $50 \mathrm{~mL}$ of solvent. The prototype flasks were fitted with ground glass stoppers with an inlet tube reaching below the solvent surface and an outlet tube remaining above the solvent surface. The iodine test gas was bubbled through the solvent at a flow rate of $0.05 \mathrm{~L} \mathrm{~min}^{-1}$. The prototype traps were wrapped in foil to 

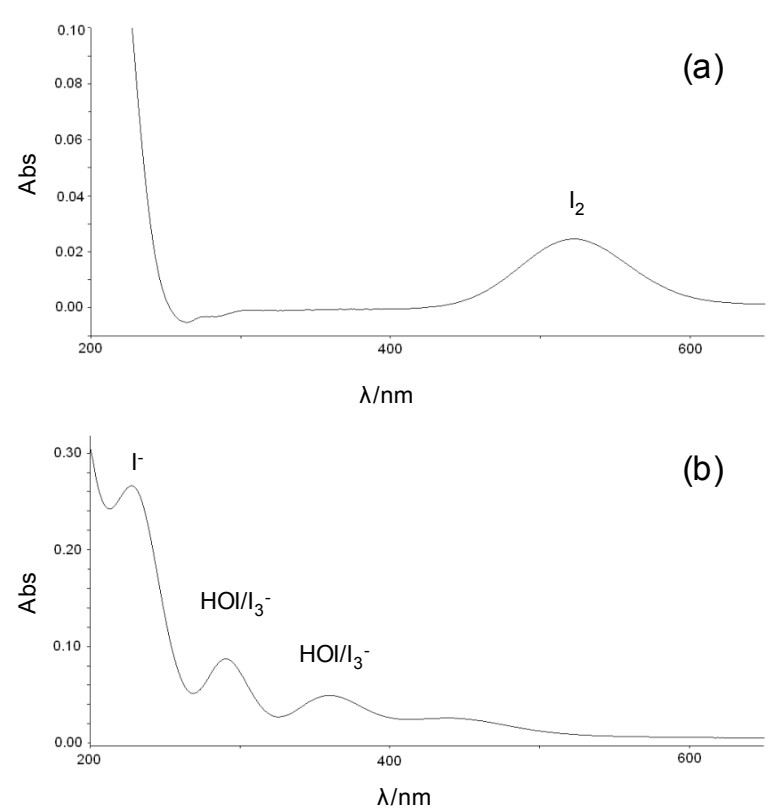

Fig. 1. Absorption spectrum of (a) $5 \times 10^{-5} \mathrm{M}$ molecular iodine in $n$-hexane and (b) $5 \times 10^{-5} \mathrm{M}$ molecular iodine in ethanol.

prevent photolysis of molecular iodine and immersed in an ice/ sodium chloride $\left(-9^{\circ} \mathrm{C}\right)$ cold bath to minimise solvent evaporation.

The traps were deployed for periods of up to three hours and the iodine content determined spectrometrically. The recovery and trapping efficiency were determined using two traps in series as for the denuder tubes. The evaporation rate of the solvents under the trapping conditions was determined by bubbling with compressed air at $0.05 \mathrm{~L} \mathrm{~min}^{-1}$ and measuring the volume lost over time.

\subsubsection{Optimisation of the hexane trap method}

Upon establishing that hexane was the more suitable solvent (see Sect. 3.2.1), various improvements were made to the method to reduce the LoD as far as possible. The optimised solvent traps were set up as shown in Fig. 2. To increase the sensitivity of the spectrophotometric detection a $10 \mathrm{~cm}$ pathlength cell was used instead of a $1 \mathrm{~cm}$ cell. To further reduce solvent evaporation, and thus increase the length of time for which trapping can occur, an acetone/dry ice bath $\left(-50^{\circ} \mathrm{C}\right)$ was used in the place of the ice/sodium chloride bath. In order to enhance contact between the gaseous analyte and the solvent, the round bottomed flasks were replaced with $25 \mathrm{~mL}$ capacity gas Midget bubblers (Supelco) with glass frits fitted to the end of the inlet tube. The traps were wrapped in black tape to prevent photolysis of molecular iodine. The volume of hexane used as trapping solvent was decreased to $20 \mathrm{~mL}$ while the test gas flow rate was increased. Volumetric losses of hexane by evaporation within this new experimental set-up were investigated as a function of nitrogen flow rate.

\subsubsection{Derivatisation of molecular iodine using leuco-crystal violet}

Leucocrystal violet $\left(4,4^{\prime}, 4^{\prime \prime}\right.$-methylidynetris $(N, N$ dimethylaniline)) reacts with molecular iodine to give a violet coloured product, and consequently has been used as a reagent in iodine assays (Black and Whittle, 1967). The method was adapted for use in a hexane matrix to determine whether it could further reduce the limit of detection of the solvent traps. Briefly, $0.2 \mathrm{~mL}$ of leucocrystal violet indicator $\left(\sim 1.5 \mathrm{~g} \mathrm{~L}^{-1}\right)$ was added to $20 \mathrm{~mL}$ of hexane in an amber glass bottle, mixed for exactly one minute and the absorbance at $592 \mathrm{~nm}$ recorded.

\section{Results and discussion}

\subsection{Denuder tubes}

\subsubsection{Blanks}

The preliminary blank experiment in which coated denuder tubes were flushed with compressed air found high concentrations of iodine in the TMAH eluate $\left(5.2 \mathrm{ng} \mathrm{mL}^{1}\right)$. This was traced to contamination of the TMAH during storage and handling at the University of York, despite taking all appropriate precautions (e.g. storing in an air-tight box away from known sources of iodine compounds, using dedicated, acidwashed glassware). Subsequently, elution of the denuder tubes was conducted in laboratories at the Food and Environment Research Agency, which are thought to have lower background levels of iodine compounds due to the differing nature of work conducted there. Blank values of around 2 to $3 \mathrm{ng} \mathrm{mL}^{-1}$ or less were then achieved. For a denuder tube deployed for $12 \mathrm{~h}$ and sampling at a flow rate of $0.5 \mathrm{~L} \mathrm{~min}^{-1}$, this is equivalent to an atmospheric iodine concentration of 5 pptv. Occasionally, extremely high iodine contents were observed in blanks although the source of the contamination could not be identified. As the blank values quoted here fall within the lower range of atmospheric molecular iodine concentrations (Saiz-Lopez et al., 2006b), the method may only be suitable for measurements where iodine levels are expected to be high (over kelp beds for example) and even then great care must be taken to minimise contamination. All results presented here are blank corrected unless otherwise noted.

\subsubsection{Recovery and reproducibility}

The total amount of iodine recovered from the permeation oven outlet by two denuder tubes in series was very low, with average values of 5 and $17 \%$ for freshly coated and older tubes, respectively (Fig. 3). The recovery was also poorly reproducible - not only was there a large difference between batches (a) and (b), but within each batch the relative standard deviations were 70 and 22\%, respectively. Furthermore, 


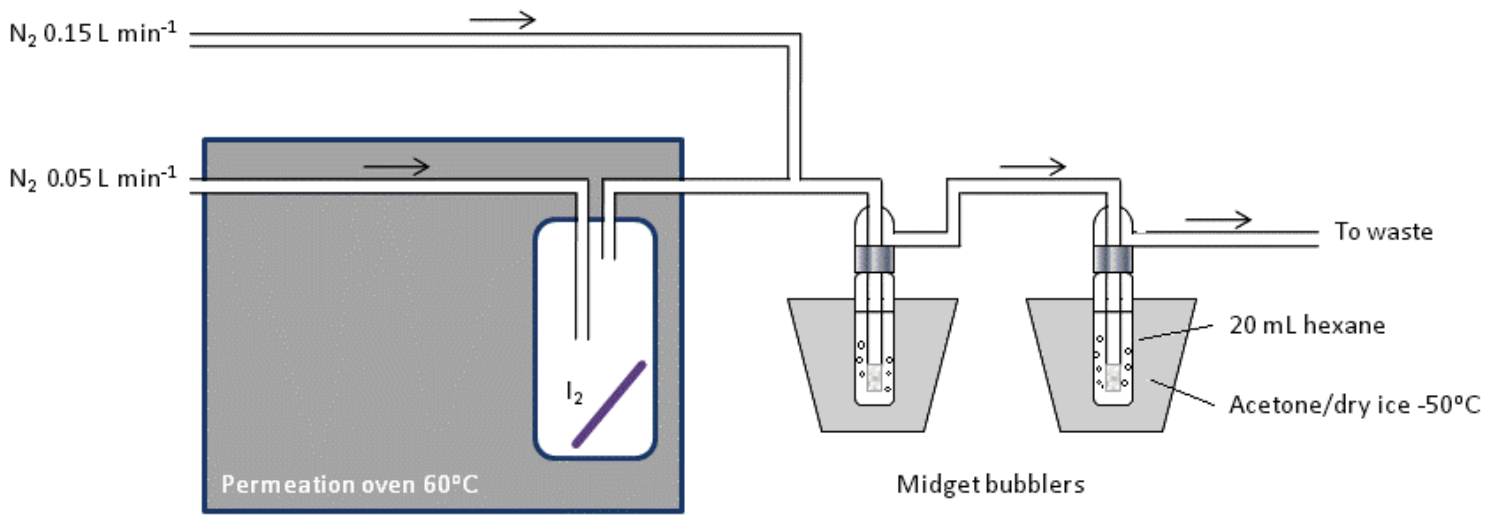

Fig. 2. Optimised solvent trap experimental set up.

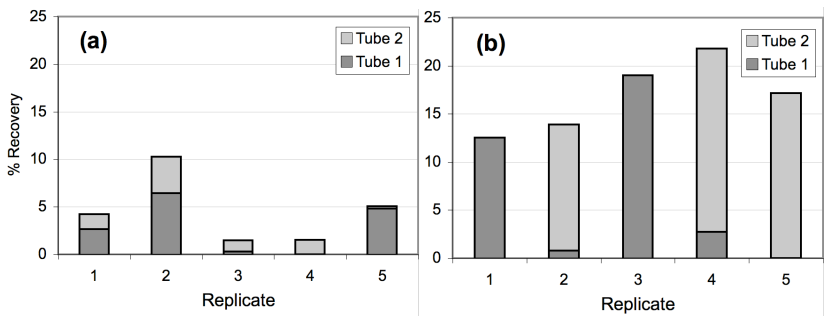

Fig. 3. Percentage recovery of molecular iodine from denuder tubes 1 and 2 in series for (a) freshly coated tubes and (b) tubes coated six months previously. Note that in (a), replicate 4 , there is no data for tube 1 .

the trapping efficiency was highly variable, with no consistent trends in the proportion of iodine retained on the first and second tube in series. Preliminary trials of the denuder tubes (results not shown) also indicated highly variable and generally low recovery of iodine from the gas stream, with values ranging from 0 to $27 \%$ for single tubes exposed for varying lengths of time and 46 to $62 \%$ for a separate batch in which two tubes in series were combined.

These results suggest that amylose-coated denuders used as described are not suitable for the quantification of molecular iodine in air. They contrast strongly with the findings of Chen et al. (2006), who report $92 \%$ recovery and $85 \%$ trapping efficiency using the same method. Given that the elution method appeared satisfactory and the ICP-MS determination step was well validated (see Sect. 2.2.3), the most likely cause of this major discrepancy, as well as the high levels of variation within the results presented here, is thought to be related to the starch coating.

The poor recoveries are not thought to be the result of saturation of the starch coating. Dry amylose can absorb $26 \%$ of its mass in iodine (Rundle and French, 1943), which equates to $1 \mathrm{mg}$ of iodine for a denuder tube coated as described here, while the total amount of iodine passed through the tubes was only $800 \mathrm{ng}$. The iodine loading was double that used in the validation of Chen et al. 2006 (480 ng), but even if the denuders were completely saturated at $480 \mathrm{ng}$ iodine, a recovery of $\sim 55 \%$ should still be observed at the higher loading. Similarly, there was no apparent relationship between recovery and concentration of the iodine test gas over the range of concentrations investigated here (Table 1). The test gas concentration used here (11 ppbv) was approximately half that used by Chen et al. 2006 (46 ppbv) but the recoveries were much lower.

Amylose may take a number of structures, of which only the single helix "V" formation is able to complex with molecular iodine under anhydrous conditions, while the more ordered "A" and "B" configurations do not (Rundle and French, 1943; Rendleman, 2003). Consequently, the protocol used to isolate amylose from starch influences the ability of the amylose to interact with iodine (Rendleman, 2003), and thus the exact type and brand of starch used is likely to affect iodine recovery by the denuder. Amylose was used here, as it is the component of starch with the highest iodine binding capacity (Bates et al., 1943) and preliminary trials using ground starch (Fluka) as per the method of Chen et al. (2006) gave low recoveries and poor reproducibility. However, it is possible the amylose had undergone retrogradation from the "V" form at some stage, rendering it less reactive to iodine. For some starches and amyloses, the presence of moisture is required for iodine binding to occur (Rendleman, 2003). This is thought to be because water loosens the starch macrostructure in a manner that aids iodine absorption. As the denuder tubes were dried and capped after coating until use and the test gas was dry, little moisture was available to facilitate iodine absorption by the starch. It is possible that the slightly better recoveries obtained using denuder tubes that had been stored for six months between coating and use (Fig. 3b) occurred because these tubes had been exposed to some moisture during storage. In summary, as absorption of iodine by starch is a function of both macrostructure (Rundle and French, 1943) and relative humidity (Rendleman, 
2003) both these factors must be strictly controlled if starch coated denuder tubes are to be used to make reproducible measurements of atmospheric iodine.

\subsubsection{Stability}

There was not a statistically significant difference in iodine content between denuders stored for one week and those analysed immediately following exposure (using a student's t-test $p=20 \%$ ). However, the lack of any significant difference was likely the result of the very high variance in both sample sets (113 and 52\% RSD, respectively) so it is not possible to draw conclusions about the stability of exposed denuder tubes from this experiment.

\subsection{Solvent traps}

\subsubsection{Comparison of hexane and ethanol}

The properties of the prototype hexane and ethanol solvent traps are summarised in Table 2. The performance of the two solvents was similar, with hexane exhibiting a lower spectrophotometric limit of detection and higher trapping efficiency. Note that while $\sim 95 \%$ ethanol is more typically used for UV spectrophotometry because it has lower levels of benzene contaminants (Williams and Fleming, 1995), absolute ethanol was used here because molecular iodine is more soluble in it (Nakanishi and Asakura, 1977). Using 95\% ethanol (Fluka), an improved spectrophotometric limit of detection of $170 \mathrm{nM}$ was achieved but this is still greater than the value obtained for hexane.

The prototype hexane trap gave $84 \%$ recovery (Fig. 4) and minimum trapping efficiency of $86 \%$ (Table 2). Calculating trapping efficiency from recovery also gives a value of 86\%; the good agreement between measured and calculated suggests that losses of iodine within the permeation system were minimal. The prototype ethanol trap appeared to give recoveries greater than $100 \%$. This is thought to be because the action of passing the test gas through the solvent trap purges it of other dissolved gases, and consequently disrupts the complex equilibria that govern the disproportionation of molecular iodine (Lengyel et al., 1993). Comparison of calibration curves prepared using pre-purged and unpurged ethanol suggested that the iodine signal at $\sim 225 \mathrm{~nm}$ (iodide) in purged ethanol may be 1.2 to 1.8 fold greater than in unpurged ethanol, resulting in overestimation of the amount of iodine trapped. Therefore, it is necessary to ensure that the calibration solution has been purged to exactly the same extent as the trap at the point of sampling, and that identical conditions of $\mathrm{pH}$ are maintained. It was not possible to correct the recovery results presented here for the effect of purging and so instead the trapping efficiency of $67 \%$ is taken as an indicator of minimum recovery.

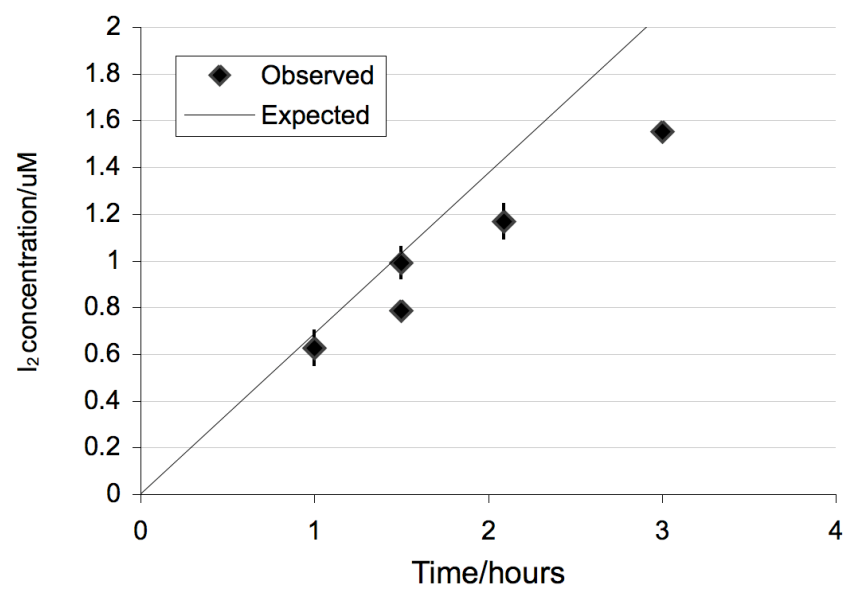

Fig. 4. Observed and expected iodine concentrations in prototype hexane solvent trap at $-9^{\circ} \mathrm{C}$. Error bars show \pm 1 standard deviation where sufficient replicates were taken.

The utility of a solvent trap also depends on the rate of solvent evaporation - the lower the evaporation rate, the longer the trap may sample for and thus the lower the limit of detection achievable. Under the prototype trapping conditions, the evaporation rates of hexane and ethanol were similar, at $1-2 \mathrm{~mL}$ per hour. Assuming a $50 \mathrm{~mL}$ starting volume, this means the traps can be used for up to four hours with less than $10 \%$ solvent evaporation. A fraction of the trapped iodine evaporates with the solvent. By evaporating iodine in hexane solutions under a stream of gently warmed $\mathrm{N}_{2}$ (to simulate the warm gas stream produced by the permeation oven), we found that the ratio of $\% \mathrm{I}_{2}$ loss to $\%$ solvent loss was $0.47 \pm 0.03(n=3)$. Therefore, $10 \%$ hexane loss equates to approximately $5 \%$ iodine loss, a level considered sufficiently low as to not be corrected for in this work.

On the basis of the performance of the two methods, it was concluded that hexane was the better solvent for the trapping of gaseous molecular iodine. Additional problems were also encountered with ethanol condensing in the fittings and tubing around the top of the solvent trap that militated against it. Using the prototype hexane trap with an ice/salt cold bath, a $1 \mathrm{~cm}$ spectrophotometer cell and a six hour trapping time ( $\sim 10 \%$ solvent evaporation) the limit of detection is estimated to be around 20 to $40 \mathrm{ppbv}$.

The trap is thought to be selective for molecular iodine over volatile organohalogens, $\mathrm{HOI}$ and $\mathrm{I}_{3}^{-}$, which all have absorption maxima at shorter wavelengths (Wall et al., 2003; Palmer and Lietzke, 1982; Paquette, 1985). However, there may be some overlap in absorption spectra between $\mathrm{I}_{2}$ and the dihalogens $\mathrm{IBr}$ and ICl, which absorb 492 and $465 \mathrm{~nm}$, respectively in $\mathrm{CCl}_{4}$ (Augdahl and Klaeboe, 1965). However, the absorption cross sections of $\mathrm{ICl}$ and $\mathrm{IBr}$ are redshifted and weaker than that of $\mathrm{I}_{2}$, so that their concentrations would have to be similar to or in excess of $I_{2}$ to comprise a significant interference. Therefore care would need to be 
Table 2. Comparison of prototype solvent trap properties.

\begin{tabular}{lcc}
\hline & Hexane & Ethanol \\
\hline LoD $_{\text {spec }}^{\mathrm{a}}, \mathrm{nM}$ & 140 & 580 \\
Evaporation rate $^{\mathrm{b}}, \mathrm{mL} \mathrm{hr}^{-1}$ & 1.2 & 1.7 \\
T. E. $^{\mathrm{c}} \%$ & 86 & 67 \\
Recovery $^{\mathrm{d}}, \%$ & $84 \pm 8$ & $>100$
\end{tabular}

a $1 \mathrm{~cm}$ cell

${ }^{b}$ Trap held at $\sim-9^{\circ} \mathrm{C}$, flow rate of $0.05 \mathrm{~L} \mathrm{~min}^{-1}$

${ }^{\mathrm{c}}$ Calculated taking LoD (spec) as the minimum concentration

d Average from 1 to $3 \mathrm{~h}$

exercised in experiments or environments where relatively high concentrations of the interhalogens are expected to be present.

\subsubsection{Optimised method}

Using a $10 \mathrm{~cm}$ cell rather than a $1 \mathrm{~cm}$ cell, the LoD was reduced approximately ten-fold to $14 \mathrm{nM}$ as expected. Derivatisation using leucocrystal violet gave a further increase in sensitivity of approximately 20 -fold. However, the reproducibility of the absorbance for a given standard concentration using leucocrystal violet was worse, with relative standard deviations in the range 4 to $16 \%$. Because of the poor reproducibility, the LoD achieved with leucocrystal violet derivatisation was higher than with hexane alone. With further work, it may be possible to develop a derivatisation method that yields reproducible results in organic solvent and a lower LoD.

Hexane evaporation rate as a function of gas flow was investigated for the improved solvent trap apparatus. At flow rates of up to $0.2 \mathrm{~L} \mathrm{~min}^{-1}$ hexane showed no appreciable loss other than that caused by uptake to the glass frit of the gas inlet (Fig. 5). Above this flow rate, evaporative losses of $0.17 \mathrm{~mL}$ per $0.1 \mathrm{~L} \mathrm{~min}^{-1}$ increase in flow rate were observed (Fig. 5). Therefore, an optimum gas flow rate of $0.2 \mathrm{~L} \mathrm{~min}^{-1}$ was selected. At this gas flow, evaporative losses were linear with time with a hexane loss rate of $0.19 \mathrm{~mL} \mathrm{hr}^{-1}$. For an initial hexane volume of $20 \mathrm{~mL}$, under the optimised conditions it would take nearly $11 \mathrm{~h}$ for $10 \%$ of the trapping solvent to be lost. While the colder trapping temperature offers improved performance in terms of solvent evaporation, it also causes any moisture in the sample gas stream to condense and subsequently freeze on the scintered frit of the inlet, blocking the system. Therefore, great care must be taken to ensure the gas stream entering the trap is completely dry. While this is practicable under many experimental situations, it may limit the applicability of the traps for sampling ambient air. Use of a Nafion box drier upstream of the solvent traps led to

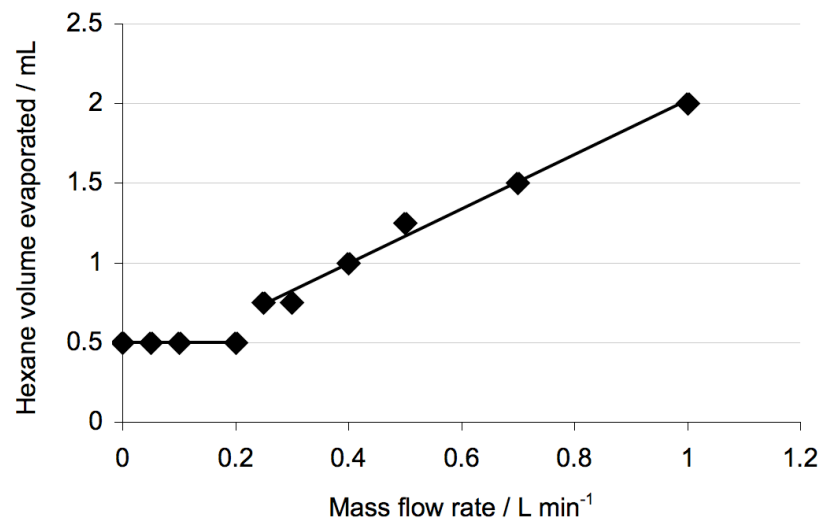

Fig. 5. Volume of hexane lost over $60 \mathrm{~min}$ at a trapping temperature of $-50{ }^{\circ} \mathrm{C}$, as a function of nitrogen flow rate.

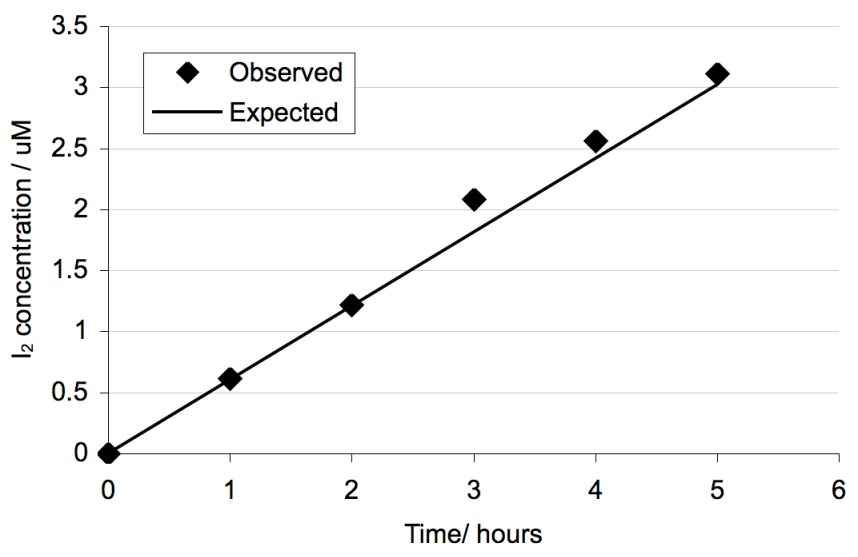

Fig. 6. Observed and expected iodine concentrations in the optimised hexane solvent trap at $-50^{\circ} \mathrm{C}$.

$\sim 60 \% \mathrm{I}_{2}$ loss, while chemical drying agents such as $\mathrm{K}_{2} \mathrm{CO}_{3}$, Drierite and molecular sieve gave 50 to $80 \% \mathrm{I}_{2}$ loss. The most suitable means of removing moisture but not molecular iodine from the gas stream identified to date has been two spiral condensers in series held at 0 and $-10^{\circ} \mathrm{C}$, but some iodine losses were still incurred.

Under the optimised trapping conditions, recovery of iodine from the permeation oven source was found to be $105 \pm 6 \%$ (Fig. 6), with no iodine detectable in the second trap (T. E. $=100 \%)$. This demonstrates that the trapping performance of the optimised trap is improved from that of the basic trap set up given in Table 2 .

Combining the improved spectrophotometric limit of detection with the enhanced trapping efficiency, longer trapping times and higher gas flow rates obtainable with the optimised trap yields a considerably improved atmospheric limit of detection for molecular iodine. For a trapping time of $10 \mathrm{~h} 45 \mathrm{~min}$ (10\% solvent loss), the atmospheric LoD is of 69 pptv and the limit of quantification (LoQ; calculated using 10 times the standard deviation of the blank) is $230 \mathrm{pptv}$. The 
LoD is comparable to peak concentrations of molecular iodine in coastal air observed at low tide (93 pptv; Saiz-Lopez et al., 2006b), suggesting the traps may be used in laboratory investigations (for example, seaweed chamber studies) at concentrations close to those observed in the atmosphere.

\section{Conclusions}

On the basis of the results presented here, it is concluded that amylose coated diffusion denuders are not suitable for the determination of molecular iodine in air. The recovery is very low and highly variable, and these problems are compounded by the difficulty of obtaining a sufficiently clean blank. If a denuder approach is required, the cyclodextrin/iodide coating (Huang and Hoffmann, 2009) is expected to give more reliable results.

Hexane or ethanol solvent traps with spectrophotometric detection of iodine species were found to give high recoveries and good reproducibility. Of the two solvents, hexane gave the better performance. Using the optimised hexane trap method, a gas phase limit of detection of $70 \mathrm{pptv}$ is achievable, which is within the upper limit of ambient levels of molecular iodine observed in the coastal marine atmosphere (Saiz-Lopez et al., 2006b). The optimised hexane trap is thus suitable for measuring molecular iodine at atmospherically relevant concentrations in experimental investigations. If a means of drying the sample gas stream without removing molecular iodine can be found, it may also be possible to use hexane traps to measure molecular iodine in air where naturally occurring concentrations are very high, such as in the vicinity of kelp beds.

Acknowledgements. During this work RC was supported by Natural Environment Research Council (NERC) UK-SOLAS grant NE/D006538/1. MS thanks the NERC for funding his $\mathrm{PhD}$ studentship. LT visited the UK to work in the Carpenter group under the ERASMUS programme for student exchange.

Edited by: F. Keppler

\section{References}

Augdahl, E. and Klaeboe, P.: Spectroscopic studies of charge transfer complexes XIII. Dimethylcyanamide and iodine, iodine monochloride and iodine monobromide, Act. Chem. Scand., 19, 807-816, 1965.

Bates, F. L., French, D., and Rundle, R. E.: Amylose and amylopectin content of starches determined by their iodine complex formation, J. Am. Chem. Soc., 65, 142-148, 1943.

Black, A. P. and Whittle, G. P.: New methods for the colorimetric determination of halogen residuals. Part I. Iodine, iodide, and iodate, J. Am. Water Works Assn., 59, 471-490, 1967.

Calabrese, V. T. and Khan, A.: Amylose-iodine complex formation without KI: Evidence for absence of iodide ions within the complex, J. Polym. Sci. Pol. Chem., 37, 2711-2717, 1999.
Chen, H., Brand, T., Bandur, R., and Hoffmann, T.: Characterization of iodine species in the marine aerosol: to understand their roles in particle formation processes, Front. Chem. Chin., 2, 119129, 2006

Dixneuf, S., Ruth, A. A., Vaughan, S., Varma, R. M., and Orphal, J.: The time dependence of molecular iodine emission from Laminaria digitata, Atmos. Chem. Phys., 9, 823-829, 2009, http://www.atmos-chem-phys.net/9/823/2009/.

Finley, B. D. and Saltzman, E. S.: Observations of $\mathrm{Cl}_{2}, \mathrm{Br}_{2}$, and $\mathrm{I}_{2}$ in coastal marine air, J. Geophys. Res., 113, D21301, doi:10.1029/2008JD010269, 2008.

Garland, J. A. and Curtis, H.: Emission of Iodine from the SeaSurface in the Presence of Ozone, J. Geophys. Res., 86, 31833186, 1981.

Harris, D. C.: Quantitative Chemical Analysis, 6th edn., 726 pp., W. H. Freeman, New York, USA, 2002.

Huang, R. J. and Hoffmann, T.: Development of a Coupled Diffusion Denuder System Combined with Gas Chromatography/Mass Spectrometry for the Separation and Quantification of Molecular Iodine and the Activated Iodine Compounds Iodine Monochloride and Hypoiodous Acid in the Marine Atmosphere, Anal. Chem., 81, 1777-1783, 2009.

Kloskowski, A., Pilarczyk, M., and Namiesnik, J.: Denudation - A convenient method of isolation and enrichment of analytes, Crit. Rev. Anal. Chem., 32, 301-335, 2002.

Küpper, F. C., Carpenter, L. J., McFiggans, G. B., Palmer, C. J., Waite, T. J., Boneberg, E. M., Woitsch, S., Weiller, M., Abela, R., Grolimund, D., Potin, P., Butler, A., Luther, G. W., Kroneck, P. M. H., Meyer-Klaucke, W., and Feiters, M. C.: Iodide accumulation provides kelp with an inorganic antioxidant impacting atmospheric chemistry, Proc. Nat. Acad. Sci. U.S.A., 105, 69546958, 2008.

Lengyel, I., Epstein, I. R., and Kustin, K.: Kinetics of Iodine Hydrolysis, Inorganic Chemistry, 32, 5880-5882, 1993.

Nakanishi, K. and Asakura, S.: Solubility of Iodine in MixedSolvents - Case-Study of Preferential Solvation in Nonpolar and Associated Solutions, J. Phys. Chem., 81, 1745-1750, 1977.

O'Dowd, C. D. and Hoffmann, T.: Coastal new particle formation: A review of the current state-of-the-art, Environ. Chem., 2, 245$255,2005$.

Palmer, C. J., Anders, T. L., Carpenter, L. J., Küpper, F. C., and McFiggans, G. B.: Iodine and halocarbon response of Laminaria digitata to oxidative stress and links to atmospheric new particle production, Environ. Chem., 2, 282-290, 2005.

Palmer, D. A. and Lietzke, M. H.: The equilibria and kinetics of iodine hydrolysis, Rad. Chim. Acta., 31, 37-44, 1982.

Paquette, J. and Beverly L. F.: Iodine chemistry in the +1 oxidation state. I. The electronic spectra of $\mathrm{OI}^{-}, \mathrm{HOI}$, and $\mathrm{H}_{2} \mathrm{OI}^{+}$, Can. J. Chem., 63, 2444-2448, 1985.

Raisbeck, G. M. and Yiou, F.: ${ }^{129}$ I in the oceans: origins and applications, Sci. Tot. Environ., 237/238, 31-41, 1999.

Rajendran, P.: Aqueous chemistry of iodine in seawater: potential chemical sources of iodine in the marine atmosphere, $\mathrm{Ph} . \mathrm{D}$. Thesis, Department of Chemistry, University of York, York, 67-68, 79-80, 2008.

Rendleman, J. A.: The reaction of starch with iodine vapor. Determination of iodide-ion content of starch-iodine complexes, Carbohydr. Polym., 51, 191-202, 2003.

Rundle, R. E. and French, D.: The configuration of starch in 
the starch-iodine complex. III. X-Ray diffraction studies of the starch-iodine complex, J. Am. Chem. Soc., 65, 1707-1710, 1943.

Saiz-Lopez, A., Plane, J. M. C., McFiggans, G., Williams, P. I., Ball, S. M., Bitter, M., Jones, R. L., Hongwei, C., and Hoffmann, T.: Modelling molecular iodine emissions in a coastal marine environment: the link to new particle formation, Atmos. Chem. Phys., 6, 883-895, 2006, http://www.atmos-chem-phys.net/6/883/2006/.

Saiz-Lopez, A., Shillito, J. A., Coe, H., and Plane, J. M. C.: Measurements and modelling of $\mathrm{I}_{2}, \mathrm{IO}, \mathrm{OIO}, \mathrm{BrO}$ and $\mathrm{NO}_{3}$ in the mid-latitude marine boundary layer, Atmos. Chem. Phys., 6, 1513-1528, 2006,

http://www.atmos-chem-phys.net/6/1513/2006/.
Saiz-Lopez, A. and Boxe, C. S.: A mechanism for biologicallyinduced iodine emissions from sea-ice, Atmos. Chem. Phys. Discuss., 8, 2953-2976, 2008,

http://www.atmos-chem-phys-discuss.net/8/2953/2008/.

Wall, M., Tarnovsky, A. N., Pascher, T., Sundstrom, V., and Akesson, E.: Photodissociation dynamics of iodoform in solution, J. Phys. Chem. A., 107, 211-217, 2003.

WHO: Iodine status worldwide: WHO Global Database on Iodine Deficiency, Department of Nutrition for Health and Development, World Health Organisation, Geneva, 2004.

Williams, D. H. and Fleming, I.: Spectroscopic methods in organic chemistry, 5th edn., McGraw-Hill Publishing Company, Maidenhead, UK, 1995. 